\title{
Cogeneration in Small Scale - High Speed Microturbines Dynamic Analysis
}

\author{
Jan KICIŃSKI \\ University of Warmia and Mazury in Olsztyn \\ Institute of Fluid-Flow Machinery \\ Polish Academy of Sciences \\ Fiszera 14, 80-952 Gdańsk, Poland \\ e-mail: kic@imp.gda.pl \\ (received May 6, 2010; accepted May 14, 2010)
}

\begin{abstract}
Main energy conversion machinery used and to be used in cogeneration systems are schematically described. Some assets of the distributed generation are pointed out and small-scale cogeneration systems designed for energy units of distributed cogeneration are described.

In the small scale, turbines and bearings are a source of specific problems connected with securing stable rotor operation. Accepted has been two kinds of high speed micro-turbines of electric power about $3 \mathrm{KW}$ with multistage axial and radial rotors supported on foil bearings. A concept which becomes more and more attractive takes into account a low-boiling agent, which is normally used in the thermal cycle of the micro-turbine, as the lubricating liquid in the bearings (so-called ORC based systems). Of some importance is the operation of these machines at a low noise emission level, sine being parts of the household equipment they could disturb the calm of the residents. The scope of the present article is limited to the discussion of dynamic characteristics of the selected design. The properties of the rotor combined with slide bearings (foil bearings in this particular case) were taken under investigation. A combination of this type is a certain novelty since a typical modal analysis of such objects refers to a rotor itself. Analysing the dynamic state of the "home" power plants requires qualitatively novel research tools.
\end{abstract}

Keywords: cogeneration, micro-turbines, rotor dynamics.

\section{Introduction}

Cogeneration is a simultaneous production of electric energy and heat which leads to a more efficient utilisation of primary energy. Thus, cogeneration brings considerable savings in the final energy production and contributes to the decrease of the level of emissions into the environment, especially of $\mathrm{CO}_{2}$. The opportunities for cogeneration are however usually determined by the demand 
on heat, which can be very important, for example seasonally and with during daytime. The complex analysis of a cogeneration unit should take into account the characteristics of the heat receiver.

Samples of quantitative gains from cogeneration are displayed in Fig. 1. As seen in the picture, in order to produce 21 units of electric energy and 33 units of heat in cogeneration (assuming the theoretical total cogeneration efficiency of 90\%) 60 units of primary energy are required, whereas 97 units of primary energy are needed to produce the same amount of final energies in separate generations.

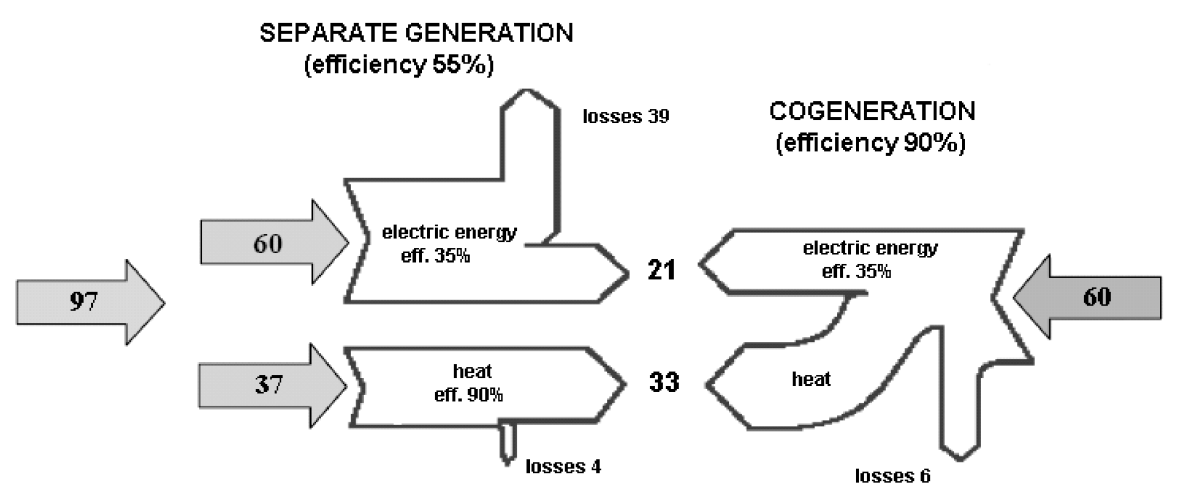

Fig. 1. Production of electric energy and heat in a separate mode and in cogeneration.

The counterparts of large power turbines in the distributed generation are small steam turbines or micro-turbines that operate in an organic Rankine cycle (ORC) which is schematically presented in Fig. 2. Main components of this CHP station are an ecological boiler fit to combust different kinds of biomass

\section{ORC}

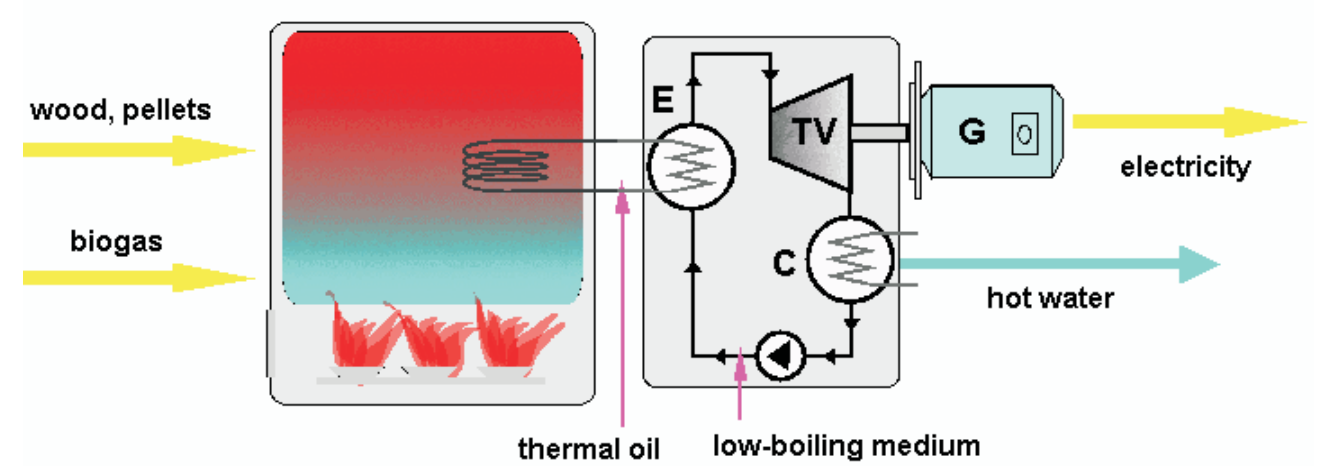

Fig. 2. Cogeneration unit with ORC; E - evaporator, TV - steam turbine, C - condenser, $\mathrm{G}$ - generator. 
or biofuels, intermediate heat cycle to extract heat from flue gases to the thermal oil as the heat carrier, evaporator, turbine with a low boiling liquid as the working medium, generator, condenser and circulating pumps of the working medium and thermal oil (Distributed Energy Peer Review, 2005; Polimeros, 2002; www.turboden.it/en/; Schmidt, 2001; Frechette, Jacobson, 2000). In the presented heat cycle, the electric energy is a by-product and forms only about 10-20\% of the total heat. Micro CHP units dedicated for individual households of total heat capacity up to $20 \mathrm{kWt}$ and electric power up to $4 \mathrm{kWe}$ are currently elaborated at IMP PAN.

Safe operation of those machines brings new challenges for designers, operators, and research workers. The operation of a turbine at rotational speed of an order of several thousand rev/min, small external loads and small dimensions of the entire machine create serious problems of keeping stable operation of the system and securing relevant durability of its particular elements. Of particular importance are here the bearings, which should secure a stable and safe operation of the entire machine. Numerous novel solutions are proposed in the form of low-friction polymer bearings, foil bearings, or various types of gas bearings. A concept which becomes more and more attractive takes into account a low-boiling agent, which is normally used in the thermal cycle of the micro-turbine, as the lubricating liquid in the bearings (so-called ORC based systems). This means operating conditions, in which a real vibroacoustic threat of those machines can take place. Of some importance is also the operation of those machines at a low noise emission level since being parts of household equipments they could disturb the calm of the residents. As we can see, analysing the dynamic state of the "home" power plants requires qualitatively novel research tools.

\section{Stability testing of high-speed rotors}

Two versions of micro-turbines - axial and radial, both of $3 \mathrm{~kW}$ power but with different rotational speeds, have been suggested (KICIŃsKI et al., 2010; RZĄDKOWski et al., 2010; KICIŃSKI et al., 2008). Different speeds derive from the necessity to avoid supersonic speeds (i.e. speeds higher than 1 Mach) at the ends of blades. High speeds at the ends of blades lead to noise and possible flow perturbations, which result in an unstable operation of the system. The main aim of the research was to find out whether suggested the system of rotors and foil bearings will not exceed the system stability limit at the assumed range of rotational speeds and if it will not generate dangerous resonances.

The general concept of the micro-turbine rotors is shown in Figs. 3 and 4, whereas the model of accepted journal bearings is shown in Fig. 5. The scope of the present article is limited to the discussion of dynamic characteristics of the selected design. 

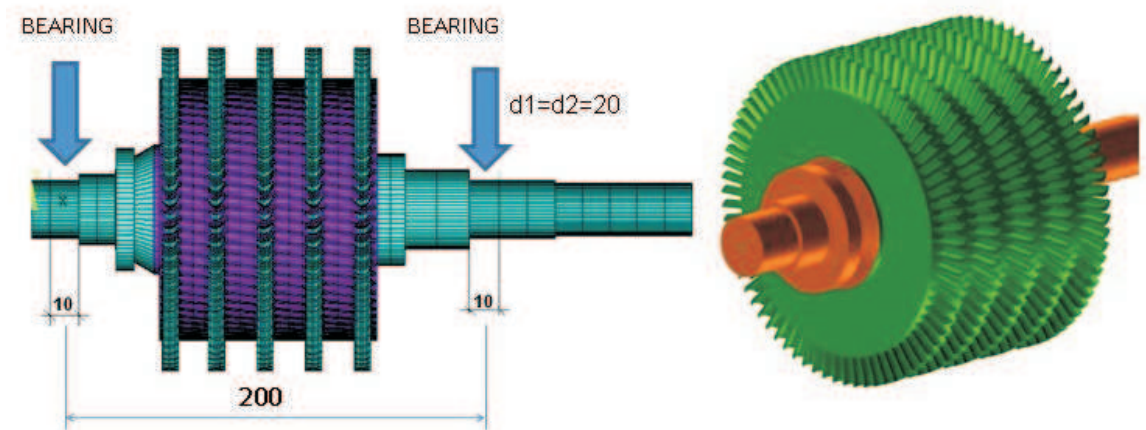

Fig. 3. Object of testing. Five - stage axial micro-turbine rotor of electric power of $3 \mathrm{KW}$ and the rotor speed $8000 \mathrm{rpm}$ (for low-boiling agents ORC). Bearing journal diameters: $\mathrm{d} 1=\mathrm{d} 2=20 \mathrm{~mm}$. Model MES: 380000 DOF (MSC Patran) (RząDKowski et al., 2010).

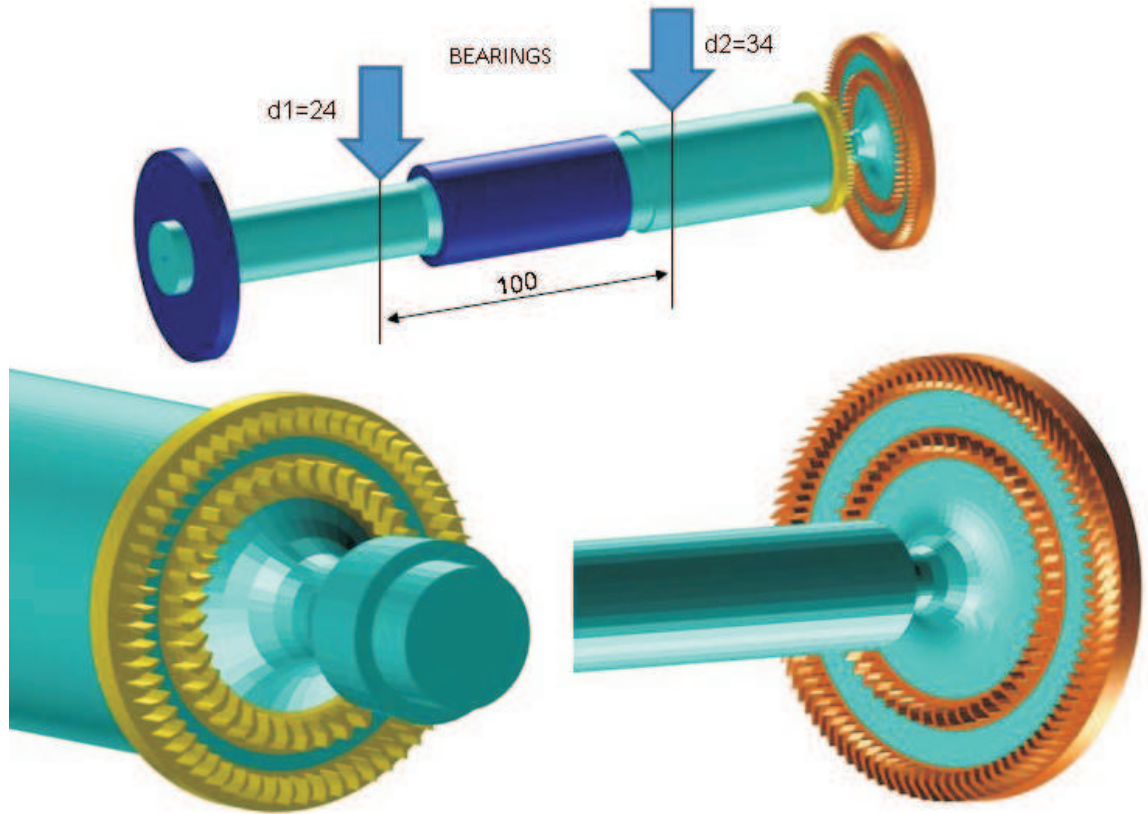

Fig. 4. Object of testing. Four - stage radial micro-turbine rotor of electric power of $3 \mathrm{KW}$ and rotor speed $23800 \mathrm{rpm}$ (for low-boiling agents ORC). Bearing journal diameters: $\mathrm{d} 1=24 \mathrm{~mm}$, d2 =34 mm. Model MES: 200000 DOF (MSC Patran) (RzĄDKowski et al., 2010).

The investigations were performed using the own MESWIR series codes, which initially have been developed for studying rotor-bearings systems in large power turbo-sets (KICIŃSKI, 2006). After introducing some modifications, they also make it possible now to study small-dimension and high-speed rotors supported on hydrodynamic and hybrid slide bearings, or even on foil bearings. The modal analyses were performed using the known commercial codes like Patran and Abaqus). 
a)

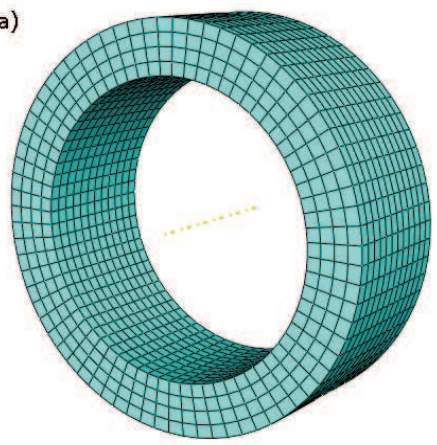

b)

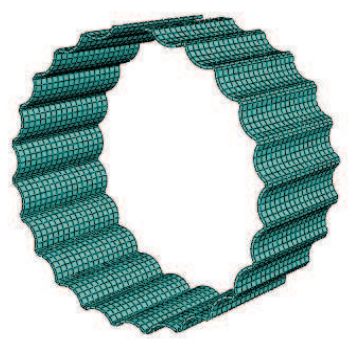

c)

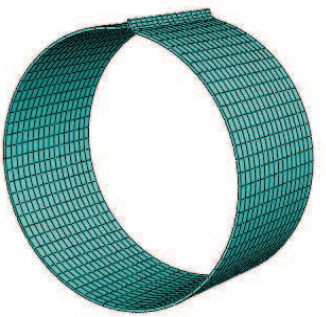

Fig. 5. FEM models of foil bearing elements ( $\mathrm{a}-$ sleeve, $\mathrm{b}-$ bump foil, $\mathrm{c}-$ top foil)

(KICIŃski et al., 2008).

The rotors were supported on foil bearings (Fig. 5), in which a low-boiling medium from the micro power plant thermodynamic cycle was used as the lubricating agent. The medium was assumed to be delivered in a liquid form to the bearing interspace. The deformation of the set of foils, caused by the pressure in the lubricating space of the bearing, was analysed using the code ABAQUS along with complementary codes worked out to transfer the data between this code and the MESWIR series codes (SCHMidT, 2001; FrechetTe, JACOBSON, 2000). The analysis of the bearing operation took into account the interaction between the medium which lubricates the bearing and the set of foils.

The results of the investigation are presented in Figs. 6-7 in the form of main stiffness coefficients of the low-boiling medium working as lubricant in the foil

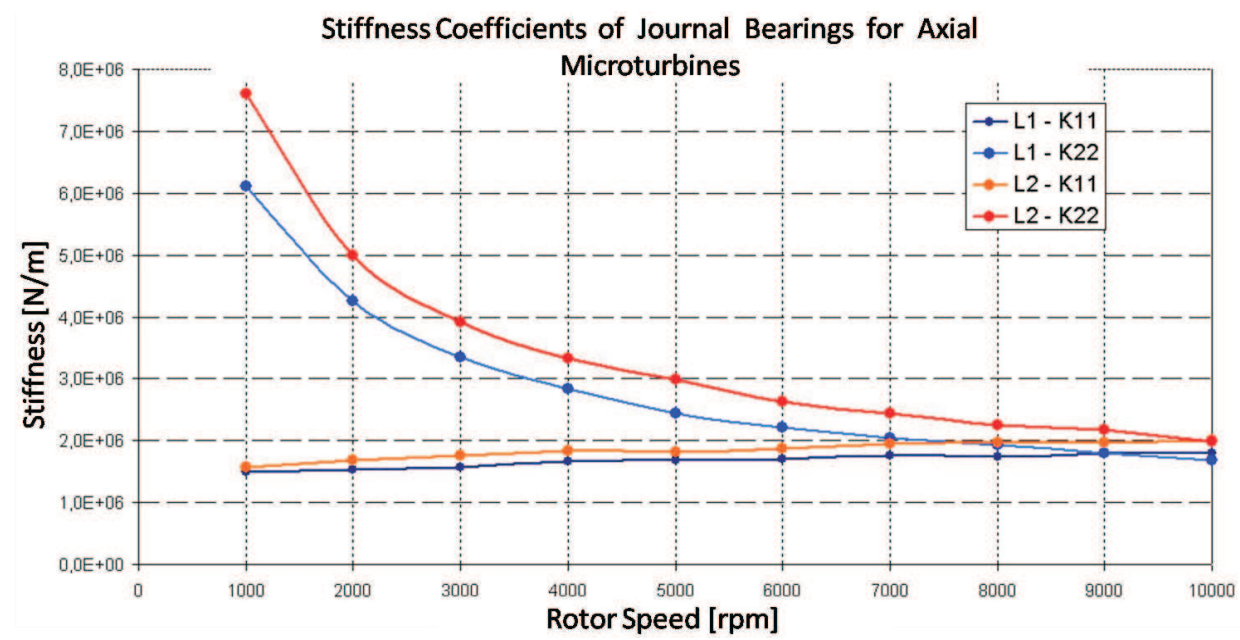

Fig. 6. The main stiffness coefficients (horizontal K11 and vertical K22) calculated for low boiling medium (lubricant) of foil bearings L1 and L2 of axial micro-turbines - Fig. 3

(KICIŃSKI et al., 2010). 


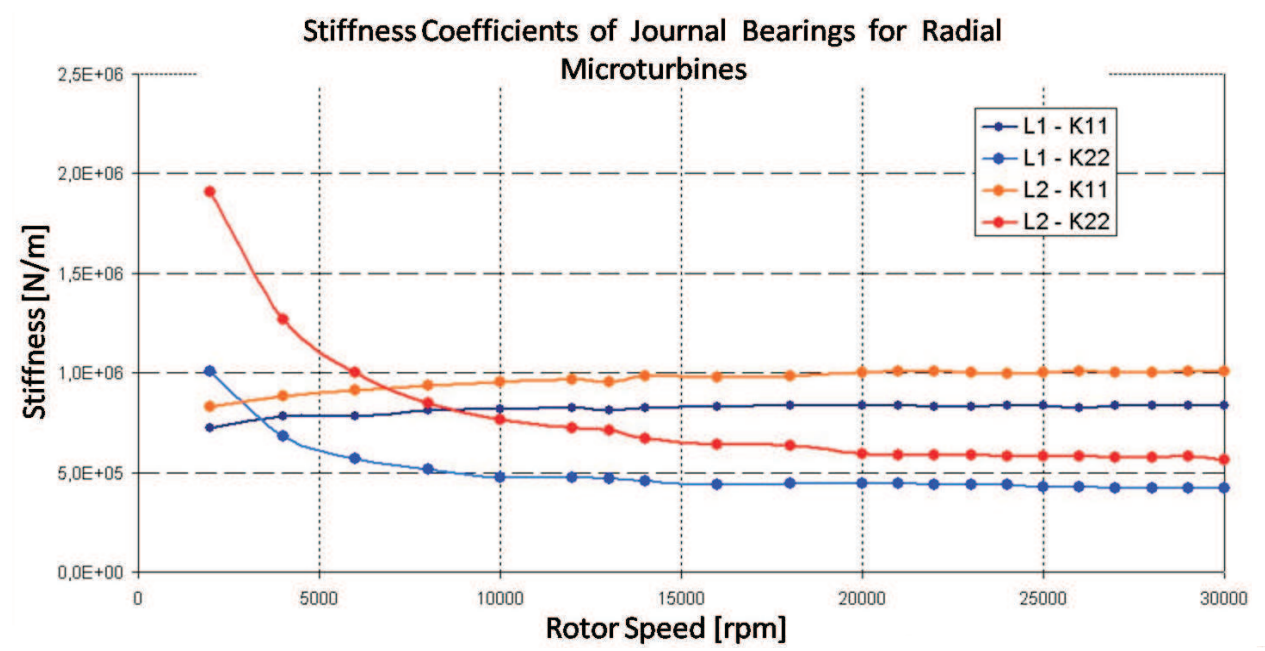

Fig. 7. The main stiffness coefficients (horizontal K11 and vertical K22) calculated for low boiling medium (lubricant) of foil bearings L1 and L2 of radial micro-turbines - Fig. 4 (KICIŃSKI et al., 2010).

bearing. These coefficients constitute the basis to determine the modal analysis of the accepted rotor - bearings system.

The first two lateral modes calculated for the rotor-foil bearing sets are presented in Fig. 8 for the axial micro-turbine and in Fig. 9 for the radial microturbine.

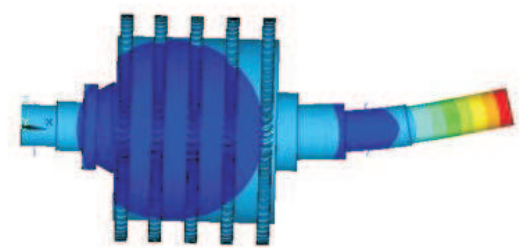

MODE $12488 \mathrm{~Hz}$

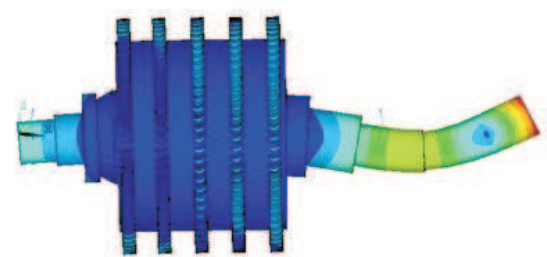

MODE $28583 \mathrm{~Hz}$

Fig. 8. Modal analysis for axial micro-turbines (set of rotor - foil bearings). The first two lateral modes (RzĄDKOWski et al., 2010).

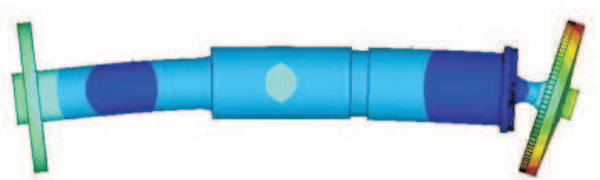

MODE $11405 \mathrm{~Hz}$

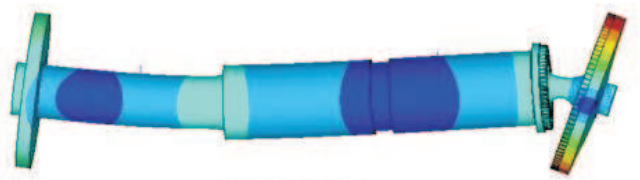

MODE 22081

Fig. 9. Modal analysis for radial micro-turbines (set of rotor - foil bearings). The first two lateral modes (RząDKowski et al., 2010). 
More important, from the practical point of view, are the amplitude - frequency responses and vibration spectra (diagnostic cards) calculated for the two kinds of micro-turbines and for proper speed regions. The results are presented in Figs. 10 and 11.
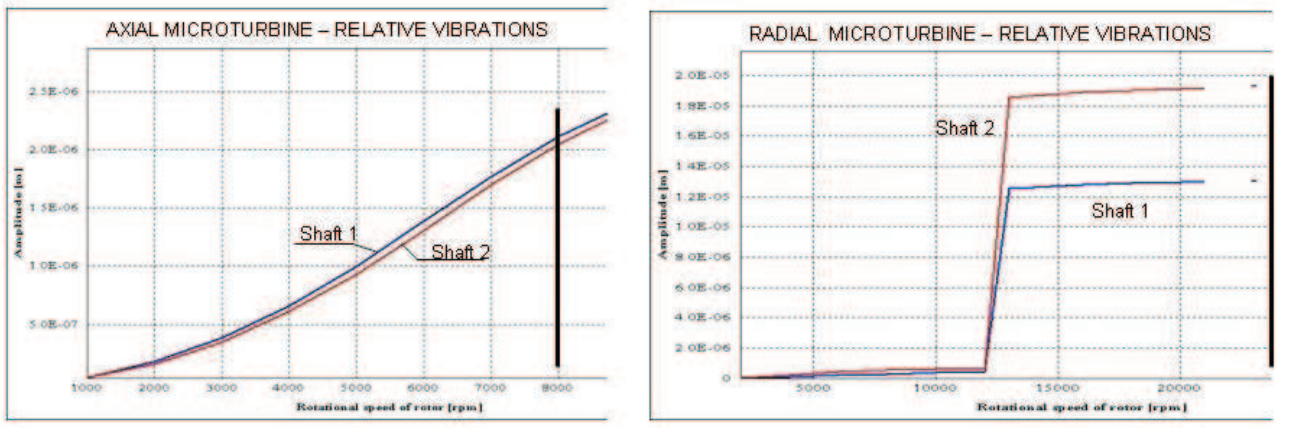

Fig. 10. Amplitude-frequency responses calculated for relative shaft-bush vibrations in bearing 1 and bearing 2 (axial micro-turbine left, radial micro-turbine right) (KICIŃsKI et al., 2010).
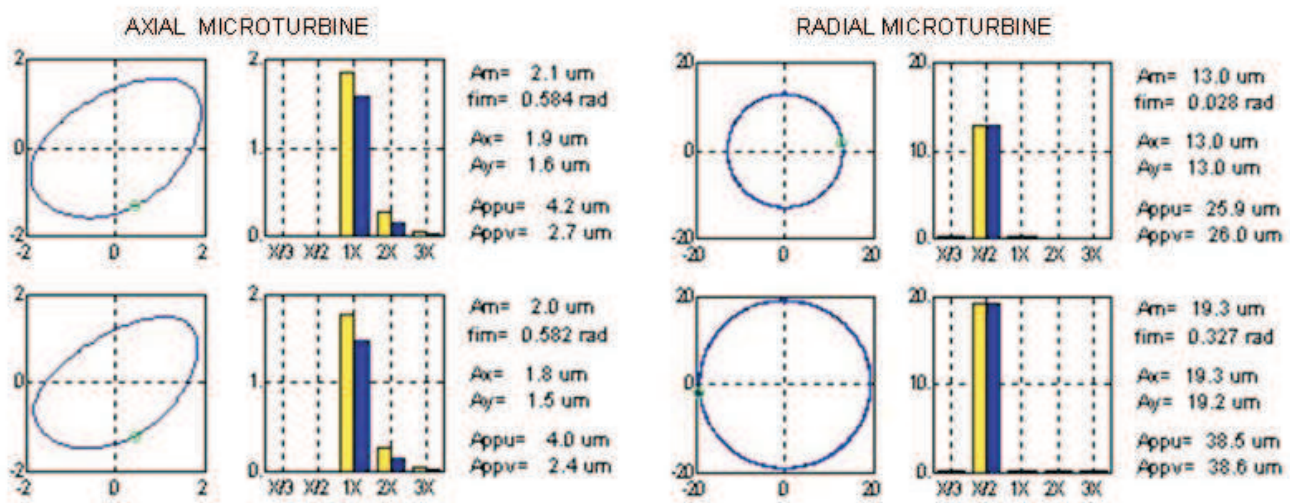

Fig. 11. Displacement trajectories and vibrations spectra calculated for relative shaft-bush vibrations in bearing 1 (upper part) and bearing 2 (lower part). Left: axial micro-turbine at rate speed $8000 \mathrm{rpm}$, right: radial micro-turbine at rate speed $23800 \mathrm{rpm}$ (KICIŃsKi et al., 2010)

\section{Conclusions}

Regarding the axial micro-turbine (with a rate rotational speed of $8073 \mathrm{rpm}$ that means $134.5 \mathrm{~Hz}$ ), the research confirmed that the rotors of the suggested construction will operate safely in the whole range of the assumed rotational speeds. The first form of eigenvalues (mode 1) occur only at $2488 \mathrm{~Hz}$ (see Fig. 8) and in the vibration spectra do not appear any subharmonic spectral lines (only the 1X synchronous component - see Fig. 11 left part). Thus, this is a exceptionally rigid construction. 
The research results in an interesting conclusion concerning the radial microturbine with a rated speed of $23800 \mathrm{rpm}(396.6 \mathrm{~Hz})$. Although modal analysis of the rotor shows the lack of possible resonance frequencies (Fig. 9, mode 1 $=1405 \mathrm{~Hz}$ ), the amplitude - frequency responses (Fig. 10 right) show a sudden increase of the amplitude much earlier before it reaches the rated speed. This increase in the amplitude is caused by exceeding the stability limit is and the system operation under a lubricant medium whip condition. It confirms the presence of the subharmonic spectral line close to $0.5 \mathrm{X}$ in the vibration spectra (Fig. 11 right). The presence of the whip means the hydrodynamic instability of the system. The vibration amplitude is almost one order of magnitude greater than in the case of the axial turbine. The above means that in case of a radial micro-turbine (Fig. 4) the suggested foil bearings and rotor construction do not meet the anticipated dynamic properties and have to be reconstructed, for example through a significant decrease of the bearing shaft diameter.

\section{References}

1. Distributed Energy Peer Review, December 2005, Darlington, USA.

2. Frechette L.G., Jacobson S.A. (2000), Demonstration of a microfabricated high-speed turbine supported on gas bearings, MIT, Solid-State Sensor and Actuator Workshop, Hilton Head Is., SC, June 4-8.

3. Kiciński J. (2006), Rotor Dynamics, IFFM Publisher, ISBN 83-7204-542-9, pp. 539, www.rotor-dynamics.imp.gda.pl.

4. Kiciński J., Żywica G., Banaszek S., Bogulicz M., Czoska B. (2008), Modelling of Thermo-Elastic Deformations of the Foil Bearing Bush with the Application of Authors' Own and Commertial Calculation Codes [in Polish], Internal Report No. 22/08 of the IF-FM PAN, Gdańsk 2008.

5. Kiciński J., Żywica G., Bogulicz M., Czoska B., Banaszek S., Bogucka K. (2010), Obliczenia sprawdzające dla wytypowanych do dalszej realizacji wariantów wirnika turbogeneratora - analiza własności dynamicznych uktadu wirnik - tożyska, Opracowanie wewnętrzne IMP PAN, Nr arch. 71/2010, Gdańsk.

6. Polimeros G. (2002), Energy Cogeneration Handbook, Industrial Press Inc.

7. Rządkowski R., Drewczyński M., Kiciński J., Żywica G. (2010), Obliczenia sprawdzajace dla wytypowanych do dalszej realizacji wariantów wirnika turbogeneratora - analiza modalna, Opracowanie wewnętrzne IMP PAN, Nr arch. 113/2010, Gdańsk.

8. Schmidt M.A. (2001), Technologies for Microturbomachinery, MIT, Transducers'01, The 11-th International Conference on Solid-State Sensors and Actuators, Munich, Germany, June 10-14.

9. Turboden, www pages, www.turboden.it/en/ 